Fabr i cat i on and Devel opment of a Novel Fl ux-Concent $r$ at i on Type Li near I nduct i on Not or

\begin{tabular}{|l|l|}
\hline 著者 & $\begin{array}{l}\text { Roy D. , Sar uhashi D. , Yamada Sot oshi , I wahar a } \\
\text { Nasay oshi }\end{array}$ \\
\hline $\begin{array}{l}\text { j our nal or } \\
\text { publ i cat i on t i t l e }\end{array}$ & I EEE Tr ansact i ons on Magget i cs \\
\hline vol une & 36 \\
\hline number & 5 \\
\hline page r ange & $3555-3557$ \\
\hline year & $2000-09-01$ \\
\hline URL & ht t p: //hdl . handl e. net /2297/48325 \\
\hline
\end{tabular}




\title{
Fabrication and Development of a Novel Flux-Concentration Type Linear Induction Motor
}

\author{
D. Roy, D. Saruhashi, S. Yamada, Member, IEEE, and M. Iwahara, Member, IEEE
}

\begin{abstract}
This paper has reported the fabrication and development of a novel flux-concentration type linear induction motor (LIM) based on the effect of flux concentration by eddy currents. In the developed LIM, the leakage flux between the yokes is reduced and as a result more flux is concentrated into the air gap. It is observed from the calculated results using equivalent circuit parameters and the experimental results that the flux-concentration type LIM (FCLIM) has better thrust-characteristics compared to that of normal type tubular LIM.
\end{abstract}

Index Terms-Conducting plate, eddy currents, flux-concentration, linear induction motor, slit, tubular induction motor.

\section{INTRODUCTION}

$\mathbf{T}$ HE DEVELOPMENT of electromagnetic pumps for pumping liquid sodium in fast breeder reactor based on the principle of the flux-concentration effect has already been reported [1]. This paper has reported the fabrication and development of a LIM utilizing the effect of flux- concentration by eddy currents [2]. The stator construction of the FCLIM is the same as that of the flux-concentration type electromagnetic pump. The mover of the FCLIM is made of a solid cylindrical iron core and either an aluminum or copper sleeve surrounding it. The conducting plate inserted between the exciting coils in each slot is the key element of this device. The leakage flux between the yokes is decreased and more flux is concentrated into the air gap, resulting in an increase of the developed thrust. The performance of the FCLIM and normal tubular LIM are determined using equivalent circuit parameters Experiments are carried out to verify the calculated results and a good agreement is found. It is observed from the calculated and experimental results that the FCLIM has better thrust-characteristics compared to that of normal type tubular LIM, The FCLIM is suited for short-stroke and lower speed applications like product distribution system, transport of materials factory automation etc.

\section{CONSTRUCTIONAL DETAILS OF FCLIM}

Fig. 1 shows a flux-concentration type 4-pole LIM, which has an annular-linear configuration. When a three-phase source is applied, a travelling electromagnetic field is produced in the air gap. The conducting plate, alongwith the exciting coil of 52 turns is inserted in each of the 12 slots. The conducting plate

Manuscript received February 3, 2000.

The authors are with the Faculty of Engineering, Kanazawa University, Kanazawa 920-8667, Japan (e-mail: roy@ magstar.ec.t.kanazawa-u.ac.jp)

Publisher Item Identifier S 0018-9464(00)07965-6.

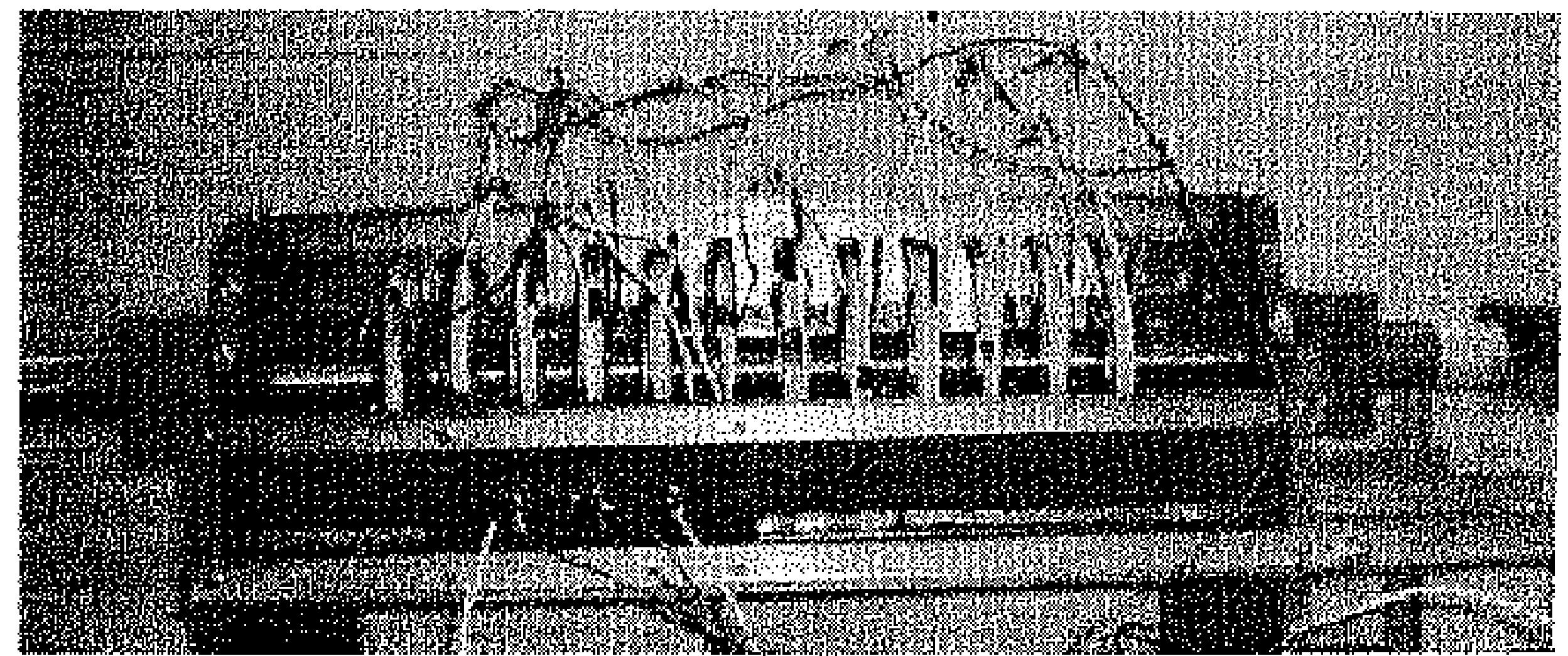

Fig. 1. Flux-concentration type LIM.

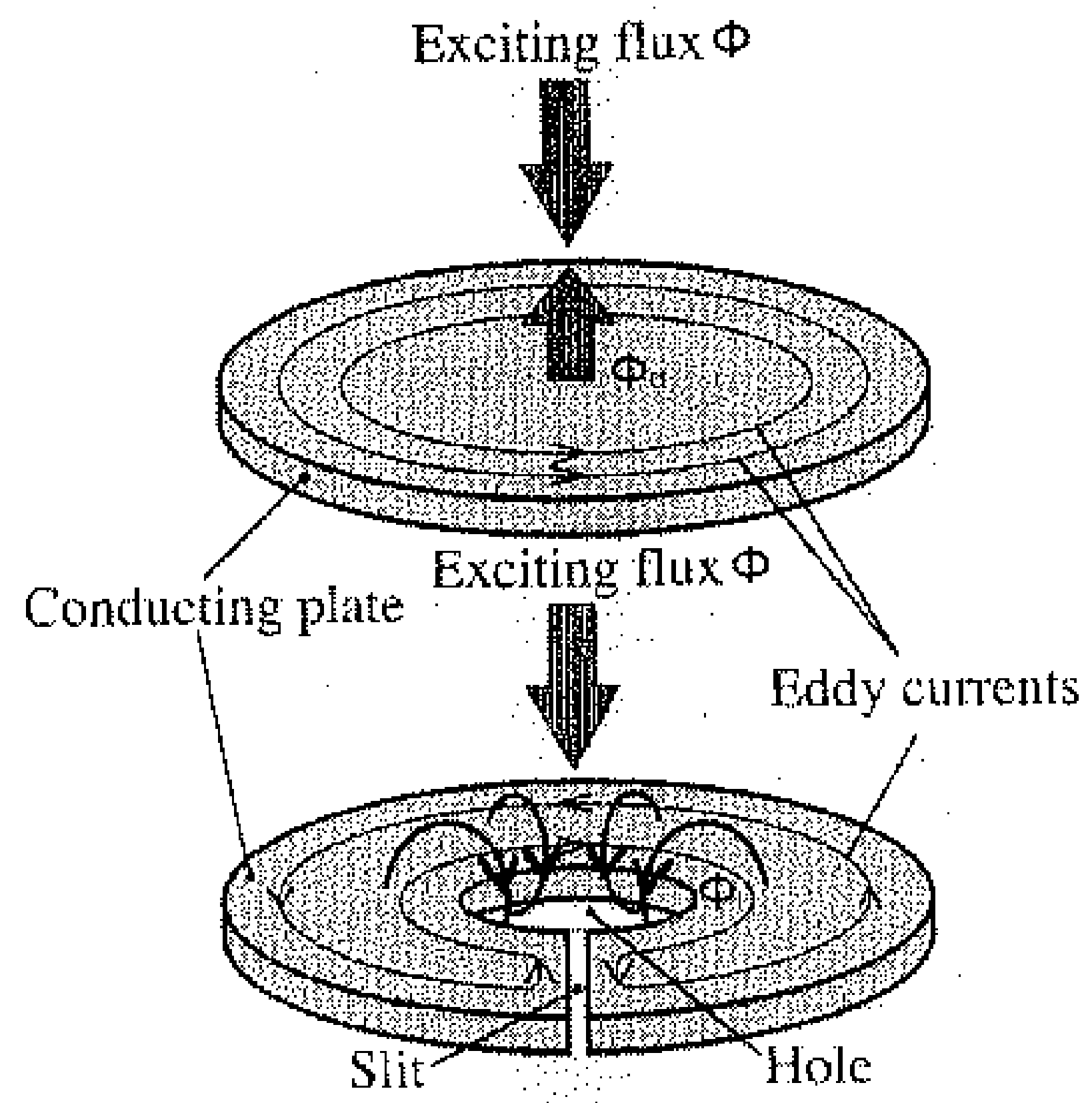

Fig. 2. Effect of the copper plate with the slit.

has an air hole in its center and a slit in the radial direction. The cross-section of the conducting plate is T-shaped. When an external alternating field is applied, eddy currents are induced in the conducting plate. The slit as shown in Fig. 2 forces the eddy currents to flow around the air hole. The induced field due to this eddy current is directed in the same direction as that of the applied field in the air gap. The plate has high reluctance, therefore, the majority of the magnetic flux is flowing through yoke, air gap and rotor core. Thus the plate with radial slit provides some sort of magnetic shield which results in reduction of the leakage flux between the yokes and concentration of flux into the air gap resulting in an increase of developed thrust. Fig. 2 shows the effect of conducting plate with the slit.

Six yokes made of laminated silicon steel are arranged radially. The length and outer diameter of the stator are $678 \mathrm{~mm}$ and $280 \mathrm{~mm}$, respectively. The pole pitch is $162 \mathrm{~mm}$. The outer diameter and thickness of the mover pipe is $54.4 \mathrm{~mm}$ and $2.5 \mathrm{~mm}$, respectively. The construction is very rugged and the end-effects are neglected. The static end effect can be neglected since it does 


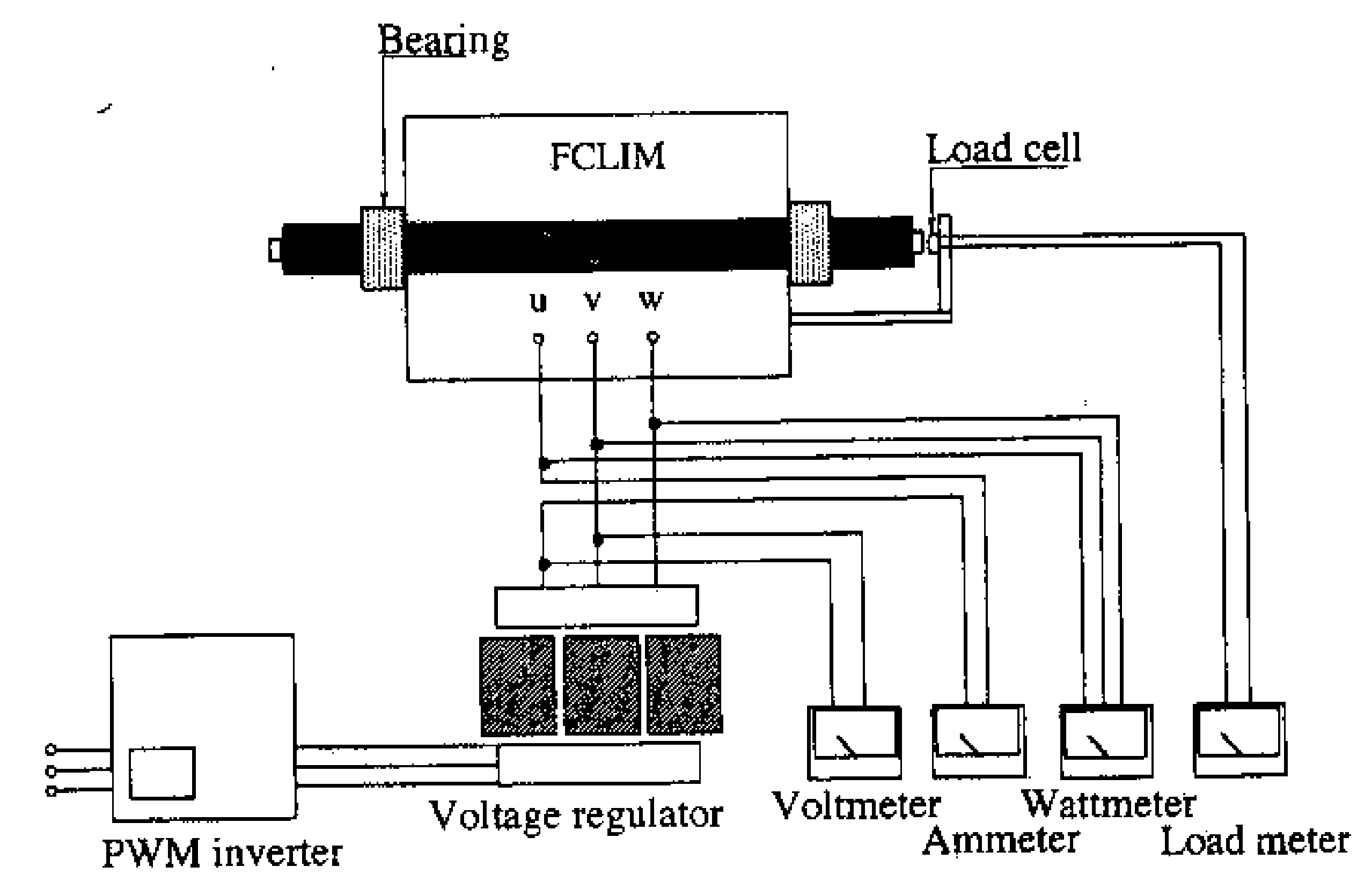

Fig. 3. Experimental setup.

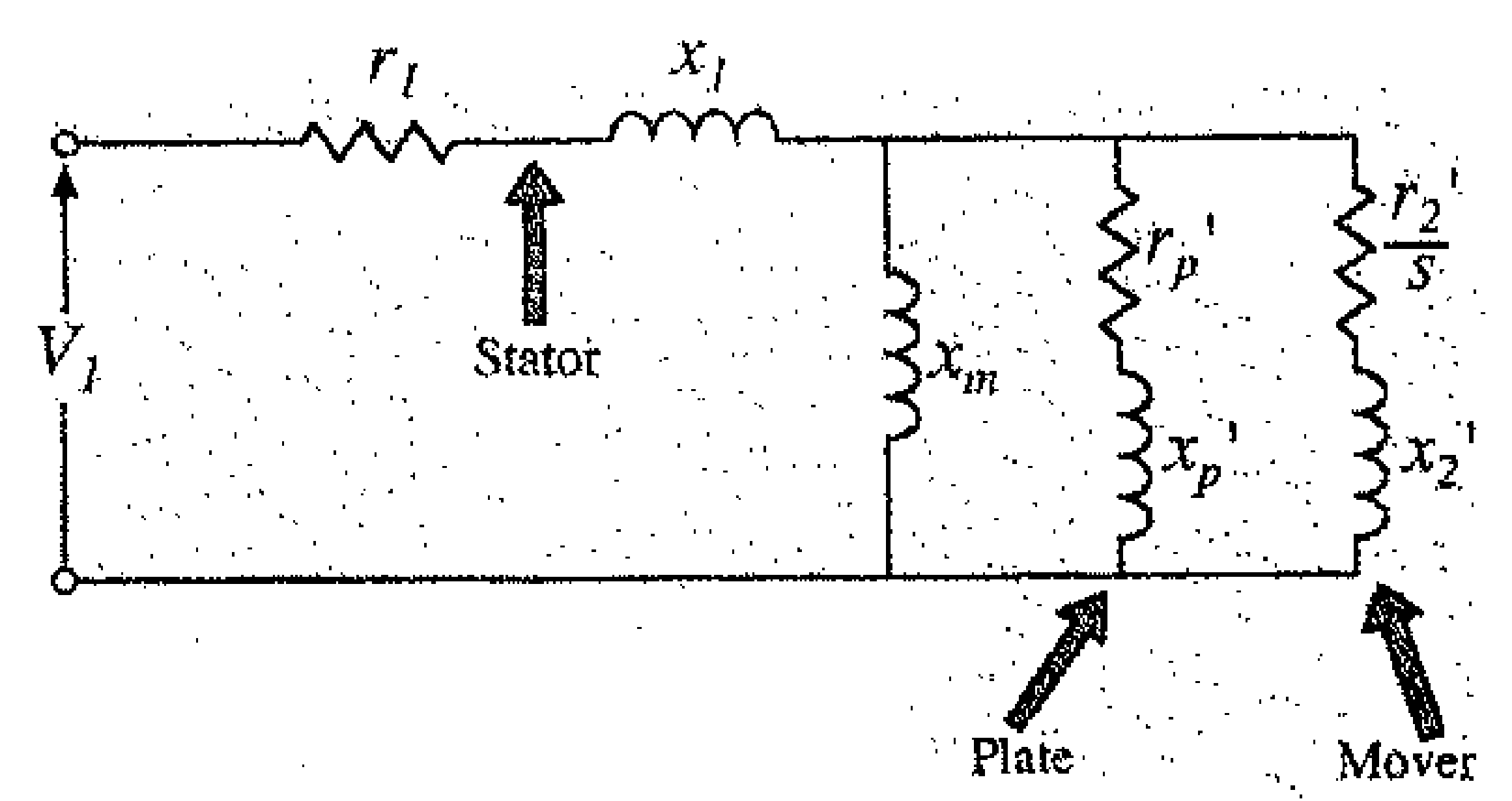

Fig. 4. Equivalent circuit of the FCLIM.

not have any end connections and the dynamic end effect can be neglected considering that the forward end effect wave is attenuated by a factor $1 / \mathrm{e}$ within 10 percent of the motor length. Furthermore, the transverse edge effect does not exist due to cÿlindrical construction.

\section{EXPERIMENTAL SETUP}

The experimental setup used for the purpose of conducting the experiments is shown in Fig. 3. In order to study the performance of the FCLIM at variable frequency operation, a PWM inverter has been used, the frequency of which is smoothly adjustable. The input voltage of the FCLIM is adjusted by using a three-phase voltage regulator, the input of which is connected to the output of the PWM inverter. The applied voltage, current, and power are measured with the help of voltmeter, ammeter and wattmeter respectively. Thrust has been measured with the help of a load cell.

\section{Performance Prediction Using Equivalent Circuit PARAMETERS}

In order to predict the performance of FCLIM the equivalent circuit of the normal three-phase induction motor has been modified and used here [3]. Fig. 4 shows the equivalent circuit of FCLIM. The mover and the plate are considered as two secondary windings of the transformer where the stator winding acts as primary winding. The parameters of two secondary windings can be considered separately and finally leads to the inclusion in one circuit. The plate impedance will act in parallel with the mover impedance. Of course there is no slip-dependent part in the plate impedance. Thus the total impedance of the circuit is decreased in the presence of the plate. In Fig. 4, $x_{m}$, $r_{1}$ and $x_{1}, r_{p}^{\prime}$ and $x_{p}^{\prime}, r_{2}^{\prime}$ and $x_{2}^{\prime}$ are the magnetizing reactance, stator resistance and leakage reactance, plate resistance and leakage reactance referred to the stator side, mover resistance and leakage reactance referred to the stator side, respectively.

The following experiments were performed for the determination of equivalent circuit parameters of the FCLIM and the normal tubular LIM.

i) Measurement of stator impedance.

ii) No load test without plate to determine the magnetizing reactance.

iii) Stalled rotor test with plate and without mover to determine the plate resistance and leakage reactance.

iv) Stalled rotor test with mover and without plate to determine the mover resistance and leakage reactance when plates are not used.

v) Stalled rotor test with both mover and plate to determine the mover resistance and leakage reactance when plates are used.

After obtaining the equivalent circuit parameters the force calculations are done as shown below.

The developed thrust

$$
F=3 \frac{I_{2}{ }^{2} r_{2}^{\prime}}{2 \tau f s} .
$$

where

$\tau \quad$ is the pole-pitch,

$f \quad$ is the frequency of the supply,

$s$ is the slip,

$r_{2}^{\prime} \quad$ is the mover resistance per phase referred to the stator side and

$I_{2}^{\prime} \quad$ is the mover current per phase referred to the stator side.

The mover current referred to the stator side is calculated using the equivalent circuit parameters.

For the FCLIM

$$
I_{2}^{\prime}=\frac{V_{1}}{\left(Z_{1}+Z_{a}\right)} \cdot \frac{Z_{b}}{\left(Z_{2}+Z_{b}\right)}
$$

For the normal type

$$
I_{2}^{\prime}=\frac{V_{1}}{\left(Z_{1}+Z_{c}\right)} \cdot \frac{Z_{m}}{\left(Z_{2}+Z_{m}\right)}
$$

where,

$Z_{m}$ is the magnetizing impedance,

$Z_{1} \quad$ is the stator impedance,

$Z_{2}$ is the mover impedance,

$Z_{a}$ is the equivalent impedance of the parallel combination of $Z_{m}$, plate impedance $Z_{p}$ and $Z_{2}$,

$Z_{b} \quad$ is the equivalent impedance of the parallel combination of $Z_{m}$ and $Z_{p}$, and

$Z_{c} \quad$ is the parallel combination of $Z_{m}$ and $Z_{2}$. 


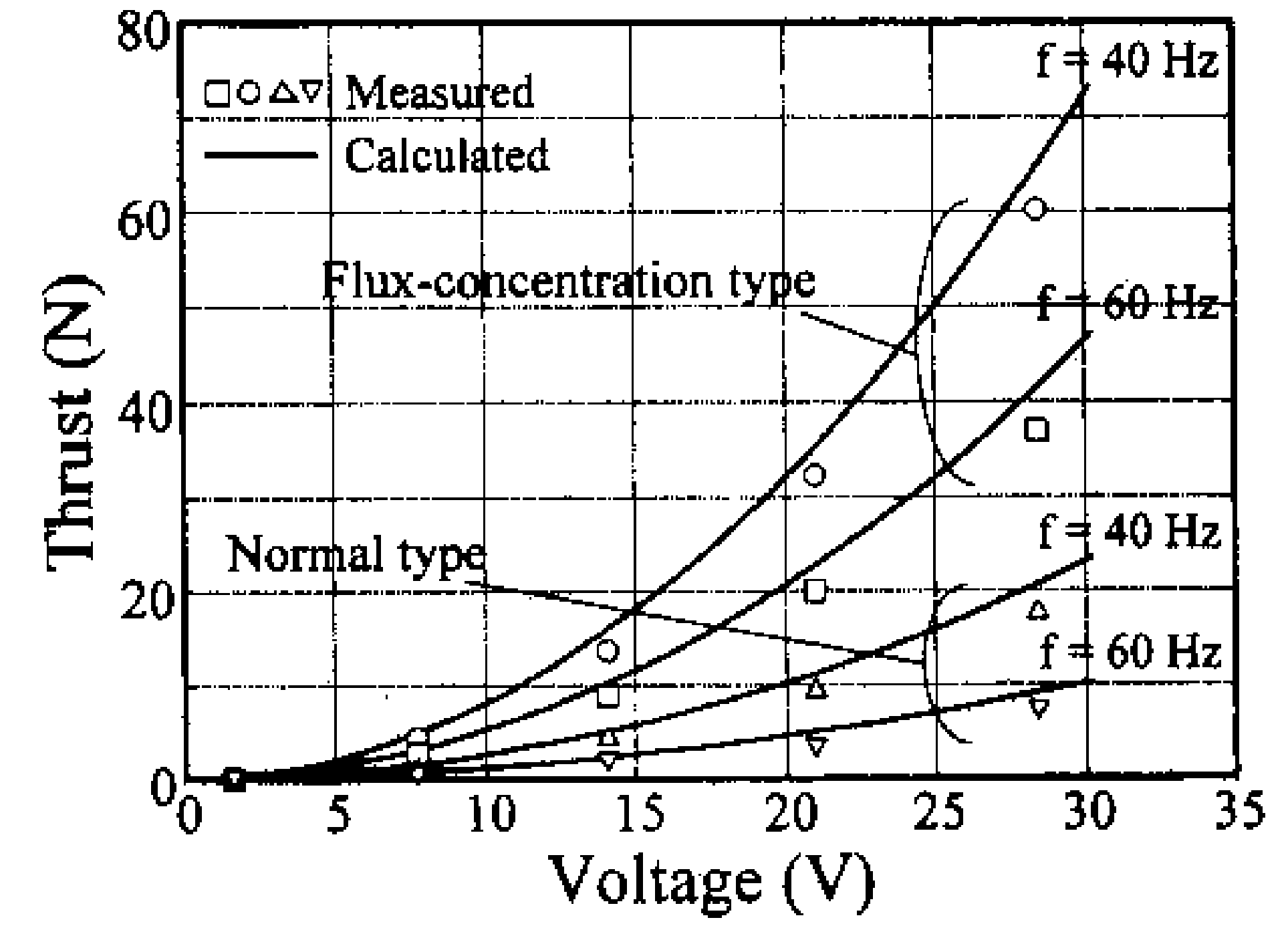

Fig. 5. Comparison of thrust versus voltage characteristics.

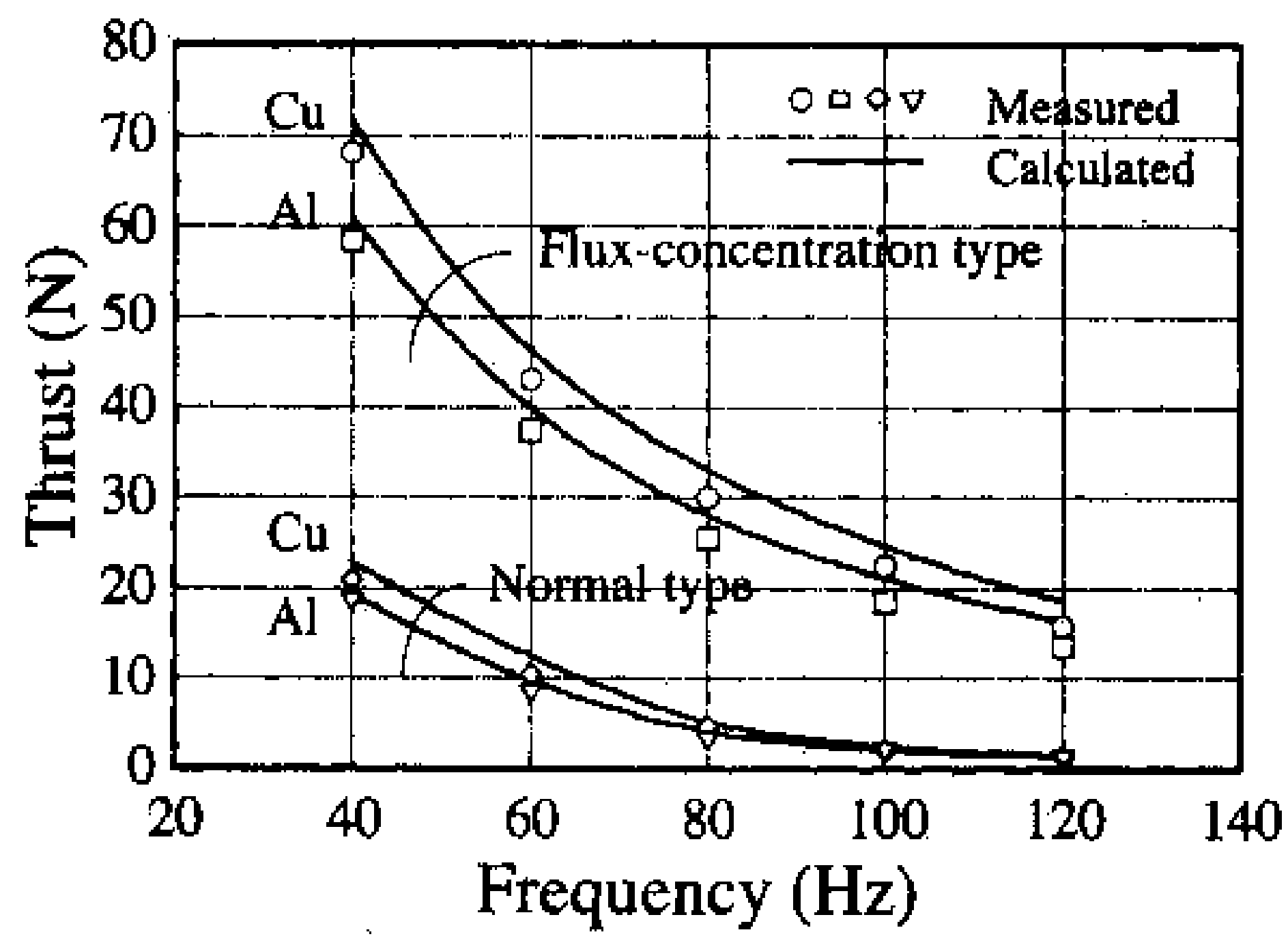

Fig. 6. Standstill thrust versus frequency characteristics.

\section{EXPERIMENTAL RESULTS}

Fig. 5 shows the thrust versus voltage characteristics of FCLIM and that of normal tubular LIM when a copper sleeve is used as mover. It is evident from these results that for a constant voltage and frequency the developed thrust in FCLIM is more than that of normal tubular LIM. Fig. 6 shows the standstill thrust versus frequency characteristics for a stator input voltage of $30 \mathrm{~V}$. Characteristics are shown for both copper and aluminum sleeve mover. It is found that for a fixed frequency the standstill thrust is more in case of FCLIM than that of normal tubular LIM.

Fig. 7 shows the thrust versus slip characteristics of FCLIM and normal type tubular LIM at a stator supply frequency of $40 \mathrm{~Hz}$ using copper sleeve as mover. Due to the flux-concentration effect in FCLIM, the mover leakage reactance is reduced. Thus in FCLIM the maximum thrust occurs at higher value of slip and gradually decreases as the slip decreases. It is seen that the maximum thrust for normal tubular LIM occurs at lower value of slip. It is observed that starting thrust and the thrust for lower speed applications are more in case of FCLIM than those of normal tubular LIM.

Fig. 8 shows the thrust versus apparent power characteristics of FCLIM and normal tubular LIM at a stator supply frequency of $60 \mathrm{~Hz}$ using copper sleeve as mover. It is observed that for a constant input kVA developed thrust is more in case of FCLIM.

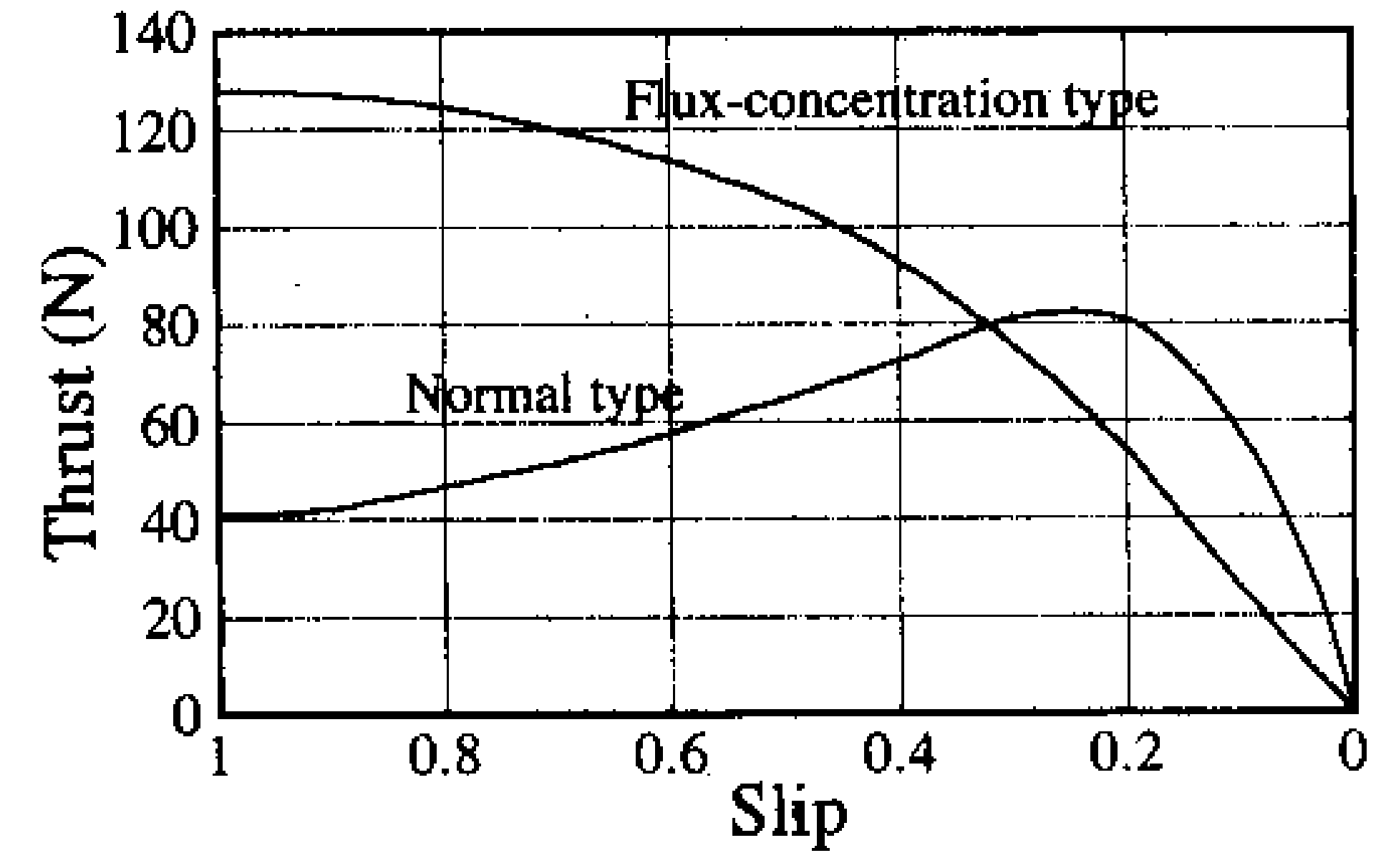

Fig. 7. Comparison of thrust versus slip characteristics (at $40 \mathrm{~Hz}$ ).

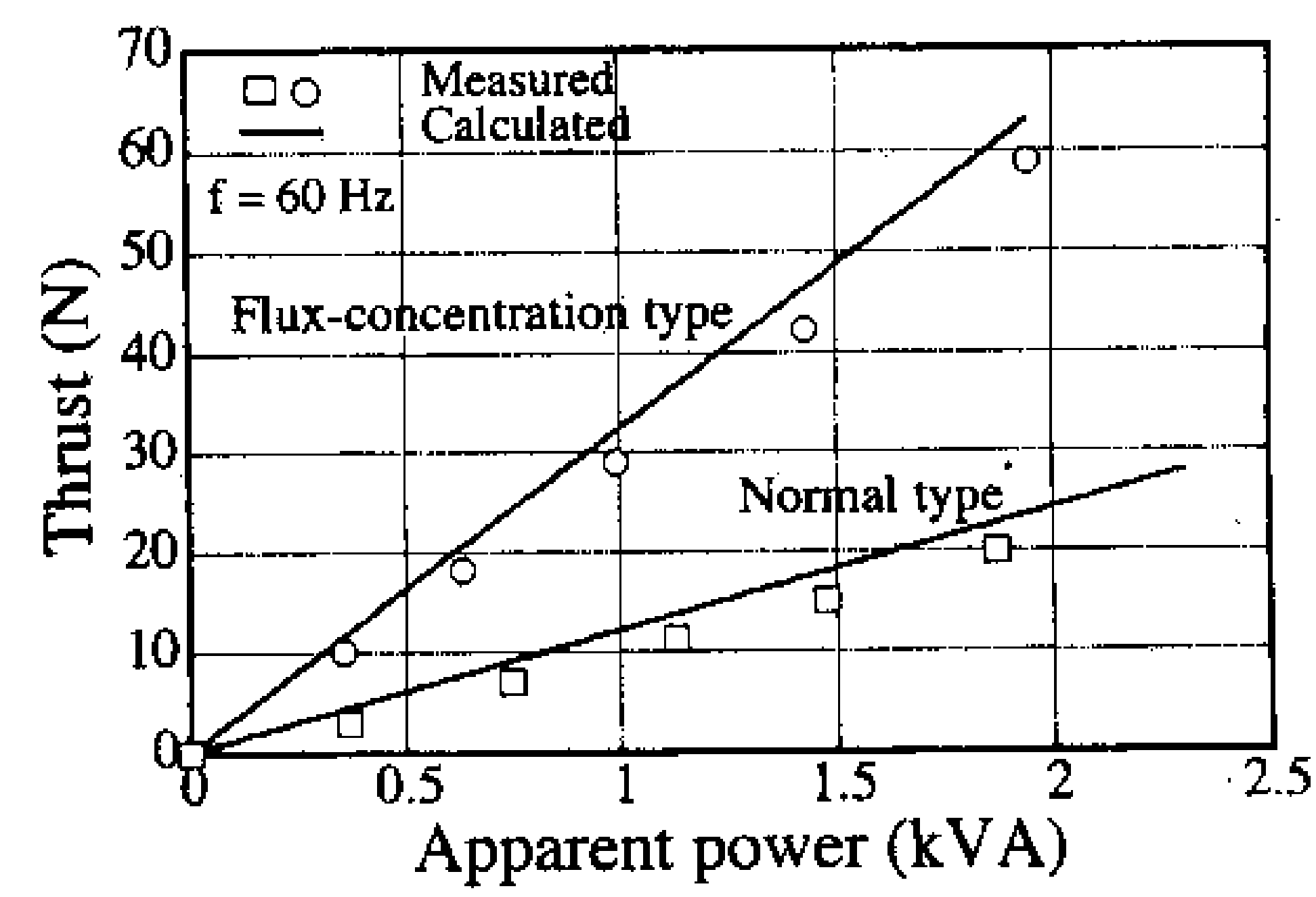

Fig. 8. Thrust versus apparent power characteristics.

Since the core losses of the FCLIM could not be accurately determined, it was not possible to compare the efficiency of the FCLIM to that of normal tubular LIM.

\section{CoNCLUSIONS}

This paper has presented the construction and performance of a novel flux-concentration type LIM. From the experimental and calculated results it can be concluded that due to the effect of flux-concentration in FCLIM, the leakage flux is reduced considerably and the air gap flux is increased. For a constant input kVA the developed thrust is more in FCLIM than that of normal type tubular LIM. The close agreement between the experimental results and calculated results using equivalent circuit parameters has confirmed the validity of the developed equivalent circuit of the FCLIM. The developed FCLIM is best suited for short-stroke and lower speed applications.

\section{REFERENCES}

[1] K. Bessho, S. Yamada, T. Yamazaki, and H. Mamada, "Flow rate characteristics of flux-concentration type electromagnetic pump," in J. Simulation and Design of Applied Electromagnetic Systems: Elsevier Science, 1994, pp. 511-514.

[2] K. Bessho, S. Yamada, M. Kooto, M. Hayashigishi, and M. Furuta, "Analysis of a novel laminated coil using eddy currents for ac high magnetic field," IEEE Trans. Magn., vol. 25, no. 4, pp. 2855-2857, July 1989.

[3] V. V. Vadher and I. R. Smith, "Performance of a segmented rotor tubular linear induction motor," IEEE Trans. Magn., vol. 29, no. 6, pp. 2941-2943, Nov. 1993. 